SCIENTIFIC LETTER

\title{
Secondary prevention of coronary heart disease in South Wales: a survey following myocardial infarction
}

\author{
P M Underwood, L S Cozma, K Laji, H Cohen, K Oboubie, P Beck
}

Heart 2004;90:1332-1333. doi: 10.1136/hrt.2003.010942

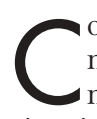
oronary heart disease (CHD) remains a major cause of morbidity and mortality in the UK. Following a myocardial infarction (MI) the risk of disease progression is high. Modification of vascular risk factors in such patients-secondary prevention-is particularly effective with evidence supporting use of antiplatelet agents, oral anticoagulants, $\beta$ blockers, angiotensin converting enzyme (ACE) inhibitors, statins, and smoking cessation. Good diabetic control and provision of cardiac rehabilitation are also important.

The aim of this study was to assess the level of secondary prevention for CHD. We based the current survey on the experience we had with a previous smaller audit conducted between 1998-99. ${ }^{1}$

\section{METHODS}

The audit departments from the University Hospital of Wales in Cardiff, Llandough Hospital, Cardiff, Royal Gwent Hospital, Newport, and Prince Charles Hospital Merthyr Tydfil, assisted in our survey; each generated a list of patients discharged between 1 January and 31 December 1999 following a new MI (International classification of diseases, 10th revision (ICD-10) codes 121.0-121.4, 121.9, 122.0, 122.1, $122.8,122.9)$. One hundred patients were randomly selected from each hospital. Pro-formas modified from our previous audit were completed to assess CHD secondary prevention. Each set of medical and nursing records was assessed independently by two specialist registrars. Pro-formas were then compared, differences discussed and, with further reference to the case notes, resolved.

Questionnaires (maximum of two) were then sent to surviving patients requesting a current medication list, details of aspirin use, smoking status, and involvement in coronary rehabilitation.

All data were made anonymous and entered into a computer database. Statistical analysis and randomisation was performed using SPSS version 7.5.

\section{RESULTS}

Three hundred and fifty six (89\%) patient records were examined. Of these 57 were found to be unsuitable (incorrectly coded or died during admission), leaving 299 records for further analysis. Mean age was 67.2 years, $71 \%$ male, mean inpatient stay 9.4 days; $44 \%$ of patients had previous vascular disease with $20 \%$ having had at least one previous MI. According to the ECGs, $40 \%$ were inferior wall MIs, 34\% anterior, 3\% posterior, $4 \%$ left bundle branch block, and $19 \%$ indeterminate. Two hundred and seven patients were followed up at a mean of 20 months post-discharge ( $86 \%$ response rate). Fifty eight unsuitable patients (deceased, living outside the area or with dementia) were not sent questionnaires.

Taking contraindications into consideration, appropriate aspirin use was $98 \%$ from discharge to follow up. At discharge $\beta$ blockers were prescribed or contraindicated in
$94 \%$ with $80 \% \beta$ blocker continuation at follow up. Heart failure was demonstrable in 187 (63\%) patients, $124(66 \%)$ of whom were on ACE inhibitors (or angiotensin II blockers) at discharge (78\% appropriate use given contraindications in 23 patients). There was a marginally significant increase in total ACE inhibitor prescribing between discharge and follow up ( $53 \%$ to $57 \%, p=0.043$, Wilcoxon signed rank test), but no significant increase in prescribing or dose escalation in the cohort with left ventricular failure (LVF).

Lipids were measured in 272 (91\%) patients, 86\% within 24 hours of admission. Mean total cholesterol (TC) was $5.70 \mathrm{mmol} / \mathrm{l} ; \geqslant 5.0 \mathrm{mmol} / \mathrm{l}$ in $198(66 \%)$ patients. By all criteria (TC assayed and management of high results) statin use was appropriate in $235(79 \%)$ patients. Mean statin doses at discharge were 18, 16, and $24 \mathrm{mg}$ for simvastatin, atorvastatin, and pravastatin, respectively. There was no significant change in statin prescription rates or dose titration between discharge and follow up.

At the time of MI $46 \%$ of patients were smokers and $65 \%$ had documented evidence of advice to quit. At follow up $88 \%$ of patients recalled being given advice to stop smoking and $55 \%$ indicated they had quit. Forty (13\%) patients were known to have diabetes mellitus (DM). In those with unknown DM status, admission blood glucose was $<11.1 \mathrm{mmol} / \mathrm{l}$ in $205(69 \%)$ patients, but not measured in $33(11 \%)$ patients. Where blood glucose was high, $10(3.3 \%)$ patients had no further assessment and 11 (3.7\%) patients had a fasting blood glucose concentration; five patients were in the diabetic range and six were normal. Two hundred and ninety seven (99\%) patients had pre-discharge blood pressures recorded; 260 (87\%) averaged $\leqslant 140 / 80 \mathrm{~mm} \mathrm{Hg}$. The $37(12 \%)$ patients with persisting hypertension were on more antihypertensive drugs at discharge than admission (1.57 v 0.97, $\mathrm{p}<0.001$, Wilcoxon signed rank test), with a further increase at follow up (1.96 $v 1.57, \mathrm{p}=0.007)$.

From the 183 replies, $138(66 \%)$ patients recalled being offered cardiac rehabilitation sessions.

\section{DISCUSSION}

Continuing widespread under use of effective treatments was the conclusion when CHD secondary prevention was last assessed in the EuroAspire II study. ${ }^{2}$ Our survey does not support these findings. We have found that post-MI, many patients are receiving appropriate advice and secondary prevention.

As in our previous survey ${ }^{1}$ we demonstrate failure to upwardly titrate ACE inhibitor doses. Many patients with LVF remained on doses lower than those used in heart failure trials. With evidence favouring early (0-36 hours) ACE inhibition post-MI, use of dose titration packs, and our

Abbreviations: $A C E$, angiotensin converting enzyme; $C H D$, coronary heart disease; DM, diabetes mellitus; LVF, left ventricular failure; MI, myocardial infarction; TC, total cholesterol 
Table 1 Aspirin, $\beta$ blocker, ACE inhibitor and statin use

\begin{tabular}{|c|c|c|c|c|c|c|c|c|}
\hline & \multicolumn{2}{|c|}{ Antiplatelet or warfarin } & \multirow[b]{2}{*}{ B Blocker } & \multicolumn{2}{|c|}{$\begin{array}{l}\text { ACE inhibitor or angiotensin II } \\
\text { blocker }\end{array}$} & \multicolumn{3}{|l|}{ Statin } \\
\hline & Aspirin & Any & & All patients & $\begin{array}{l}\text { Patients with } \\
\text { LVF }\end{array}$ & All patients & $\begin{array}{l}\text { Cholesterol } \geqslant 5.0 \\
\text { (all ages) }\end{array}$ & $\begin{array}{l}\text { Cholesterol } \geqslant 5.0 \\
\text { (age } \leqslant 75 \text { ) }\end{array}$ \\
\hline \multicolumn{9}{|l|}{ At admission } \\
\hline Taking drug & $82(27 \%)$ & 99 (33\%) & $52(17 \%)$ & 55 (19\%) & $34(18 \%)$ & 32 (11\%) & $12(6 \%)$ & $11(7 \%)$ \\
\hline ACE-I dose* & - & - & - & $5.9 \%$ & $4.6 \%$ & - & - & - \\
\hline \multicolumn{9}{|l|}{ At discharge } \\
\hline $\begin{array}{l}\text { Taking drug } \\
\text { Valid exclusion }\end{array}$ & $\begin{array}{c}255(85 \%) \dagger \\
38(13 \%)\end{array}$ & $286(96 \%) \dagger$ & $\begin{array}{l}180(60 \%) \dagger \\
102(34 \%)\end{array}$ & $\begin{array}{l}159(53 \%) \dagger \\
-\end{array}$ & $\begin{array}{c}124(66 \%) \dagger \\
23(12 \%)\end{array}$ & $180(60 \%) \dagger$ & $\begin{array}{c}149(75 \%) \dagger \\
12(6 \%)\end{array}$ & $\begin{array}{c}129(83 \%) \dagger \\
9(6 \%)\end{array}$ \\
\hline ACE-I dose* & - & - & - & $18.7 \% \dagger$ & $23.0 \% \dagger$ & - & - & - \\
\hline $\begin{array}{l}\% \text { appropriate use } \\
\text { across hospitals }\end{array}$ & $97-100 \ddagger$ & - & $92-96 \neq$ & - & $78-88 \ddagger$ & - & 77-93§ & - \\
\hline \multicolumn{9}{|l|}{ At follow up } \\
\hline Taking drug & $167(81 \%)$ & 199 (96\%) & $120(58 \%)$ & $119(57 \%)$ & $84(67 \%) \ddagger$ & $141(68 \%) \ddagger$ & $114(76 \%) \ddagger$ & 95 (80\%)‡ \\
\hline Stopped taking drug & 18 & 6 & 26 & 17 & 12 & 14 & 13 & 11 \\
\hline Started & 6 & 8 & 13 & 31 & 17 & 19 & 11 & 6 \\
\hline ACE-I dose* & - & - & - & $21.3 \% \dagger$ & $23.2 \% \ddagger$ & - & - & - \\
\hline
\end{tabular}

Patient data are presented as number of patients (percentage of totals).

* Mean dose expressed as \% maximum British National Formulary recommended; $\dagger p<0.001$; $\ddagger$ not significant; § $p<0.05$ (Kruskal-Wallis test); 9 p $<0.05$ (Wilcoxon signed rank test statistic for admission to discharge and discharge to follow up).

ACE-I, angiotensin converting enzyme inhibitor; LVF, left ventricular failure.

average nine day hospital stay, this situation should be remediable.

Patients with DM have twice the risk of further MI and three times the risk of cardiovascular death of non-diabetic patients. $^{3}$ We found 3\% of patients with a possible new diagnosis of DM missed, and a further $11 \%$ with no blood glucose measurements; laboratory blood glucose should be assayed in all patients at admission and scrutinised as for lipids. Further assessment, either by fasting glucose or oral glucose tolerance testing, should be undertaken whenever doubt remains.

Our survey does suffer methodological problems. Quality data depends upon accurate case notes and in the case of questionnaires on respondent honesty, question interpretation, and memory of events (as much as two years previous in our survey). The discrepancy between documented and recalled smoking cessation advice emphasises the importance of good record keeping. A further weakness is our lack of follow up on blood pressure and TC measurements. With a preference for low statin doses and no significant increase by follow up, lipid management is unlikely to be optimal. Nevertheless we have demonstrated ongoing aspirin, statin, and antihypertensive treatment, with continuation of $\beta$ blockers for at least one year. ${ }^{4}$

In spite of minor differences in age range and organisation of care, the provision of secondary prevention did not notably differ across the four acute hospitals. We believe further improvements will require a more individual approach with treatment optimised according to the needs and beliefs of each patient. Studies assessing understanding and attitude post-MI demonstrate important changes with time. ${ }^{5}$
Although initially enthusiastic, those with slow or incomplete recovery become despondent, and patients who recover quickly may subsequently dismiss risks as unimportant. Although the National Service Framework on CHD has afforded us an opportunity to improve the national CHD burden, the greater challenge of maximising individual benefit is yet to be fully realised.

\section{Authors' affiliations}

P M Underwood, L S Cozma, K Laji, H Cohen, K Oboubie, P Beck, University Hospital of Wales, Cardiff, UK

Correspondence to: Dr Paul M Underwood, University Hospital Wales, Cardiff CF72 8XR, UK; paul@penarthhaven.freeserve.co.uk

Accepted 16 February 2004

\section{REFERENCES}

1 Underwood P, Beck P. Secondary prevention following myocardial infarction: evidence from an audit in South Wales that the National Service Framework for coronary heart disease does not address all the issues. Qual Saf Health Care 2002;11:230-2.

2 EUROASPIRE II Study Group. Lifestyle and risk factor management and use of drug therapies in coronary patients from 15 countries: principal results from EUROASPIRE II Euro Heart Survey Programme. Eur Heart $J$ $2001 ; 22: 554-72$

3 Haffner SM, Lehto S, Ronnemaa T, et al. Mortality from coronary heart disease in subjects with type 2 diabetes and in nondiabetic subjects with and without prior myocardial infarction. N Engl J Med 1998;339:229-34.

4 Department of Health. National Service Framework for coronary heart disease. London: Department of Health, 2000.

5 Wiles R, Kinmonth A. Patients' understandings of heart attack: implications for prevention of recurrence. Patient Educ Couns 2001;44:161-9. 